\title{
Special Issue on Mobile Learning in Teacher Education
}

\section{Charles B. Hodges ${ }^{1}$}

Published online: 10 November 2019

(C) Association for Educational Communications \& Technology 2019

This issue of the TechTrends, the final issue of 2019, is a special issue guest edited by Drs. Tony Hall and Cornelia Connolly of the School of Education at the National University of Ireland, Galway. This team has put together a great issue for you with a theme of mobile learning in teacher education. You will find more information about the included papers in their Guest Editors' Notes. I appreciate all of the work they did to make this issue come together!

In addition to the special issue content, this issue includes some of our regular columns. Be sure to read the Rethinking Technology \& Creativity in the 21 st, Graduate Member Musings, ICT International, Leading Matters, and Book Reviews. I hope you enjoy the issue!
As always, if you are interested in submitting a manuscript to TechTrends, or if you want to be a reviewer, please contact me. Encourage your colleagues to submit their work to TechTrends, to read TechTrends, and to consider joining AECT! If you have a question about the journal, my phone number is $912-478-0497$ and my email address is chodges@georgiasouthern.edu. Email is always the best way to reach me. Also, you can follow TechTrends on Twitter: @ AECTTechTrends.

Publisher's Note Springer Nature remains neutral with regard to jurisdictional claims in published maps and institutional affiliations.
Charles B. Hodges

chodges@georgiasouthern.edu

1 Georgia Southern University, Statesboro, GA, USA 